\title{
Fear of Violence, Family Support, and Well-Being among Urban Adolescents
}

\author{
Allyson M. Drinkard1', Christopher G. Schell², Richard Adams² \\ ${ }^{1}$ Ashland University, Ashland, OH, USA \\ ${ }^{2}$ Kent State University, Kent, OH, USA \\ Email: adrinkar@ashland.edu
}

How to cite this paper: Drinkard, A.M., Schell, C.G. and Adams, R. (2019) Fear of Violence, Family Support, and Well-Being among Urban Adolescents. Open Journal of Social Sciences, 7, 86-105. https://doi.org/10.4236/jss.2019.79008

Received: August 5, 2019

Accepted: September 13, 2019

Published: September 16, 2019

Copyright $\odot 2019$ by author(s) and Scientific Research Publishing Inc. This work is licensed under the Creative Commons Attribution International License (CC BY 4.0).

http://creativecommons.org/licenses/by/4.0/

(c) (i) Open Access

\begin{abstract}
Our study examines how the fear of violence and family support influence adolescent social, psychological, and physical well-being, after controlling for exposure to violence and a range of demographic factors. We conduct a secondary analysis of the Project on Human Development in Chicago Neighborhoods $(\mathrm{PHDCN})$ data $(\mathrm{N}=1337)$ using mixed-effect, multi-level regression models for the total sample and for males only and females only samples. We find that family support is the most robust, main effects predictor in all three models and across all outcomes. Our analyses show that the fear of violence is associated with increases in social problems (especially for boys) and with decreases in self-rated health. We discuss the results and implications in light of sociological theories on the health and well-being of adolescents.
\end{abstract}

\section{Keywords}

Violence, Family Support, Adolescent, Well-Being, Gender

\section{Introduction}

The study of children's fears began over a century ago [1] and researchers have documented that, over time, their fears change based on present events, social and political issues, and concerns [2] [3]. Burnham [3] [4], using the American Fear Survey Schedule, has found that among the most common types of child and adolescent fears are being threatened with a gun, murderers, being raped, drive-by shootings, shootings, violence near home, crime, and gangs. Criminal victimization and exposure to violence is a lived reality for many teens and young adults in the United States [5]. Additionally, in the United States, increased incidents of bullying, neighborhood violence, mass shootings in public arenas, and targeted violence against immigrants and racial minorities should 
cause us to focus on the trauma experienced by adolescents and their well-being. According to data from the National Survey of Children's Exposure to Violence (NatSCEV), over $60 \%$ of youth were exposed to violence within the past year, either directly or indirectly [6]. In fact, children and adolescents have a higher risk of being exposed to violence and crime than adults [5]. In addition, youth living in poorer families and urban neighborhoods, and youth who are minorities or males are disproportionately likely to be exposed to violence [7]. In other words, young people's fear of violence is likely rational and reflects their greater risk of being victims of violence and crime [8] [9] [10]. We argue that the fear of violence is an important, but understudied, factor in kids' well-being.

\subsection{Fear of Violence and Exposure to Violence}

A fundamental shift occurred in how researchers perceive the social consequences of crime by not only considering the direct impact it has on victims, but also considering the indirect victimization, most notably, the fear of crime and victimization [11]. This change occurred as researchers acknowledged that the fear of crime in the United States is more prevalent than actual victimization [11]. In our study, we conceptualize the fear of violence as a legitimate, emotional reaction to the perception of impending victimization [11]. We recognize that the fear of violence is conceptually different from the perceived risk of victimization [10] and hypothesize that exposure to violence [12] is also conceptually distinct from fear of violence. We suggest that adolescents' general fear of violence (i.e. fear of being hurt by violence in the neighborhood, in front of their home, in their home, or at school or work), will be associated with deficits in well-being, even after controlling for exposure to violence.

\subsection{Fear of Violence and Adolescent Outcomes}

Many studies have documented what happens when youth are exposed to or victimized by violence; however, we know much less about how the general fear of violence impacts youth outcomes. Youth who have been victimized and/or exposed to violence may react by becoming very upset, experiencing intense fear, feelings of horror and helplessness [13], and have higher perceptions of danger [14]. We know that one of the most problematic aspects of exposure to violence and victimization is that multiple forms of violence co-occur and that, especially for children and adolescents, the impact is cumulative [15] [16]. For example, there are both short- and long-term negative outcomes, including problems with brain development, impulse control, empathy, anger management, problem-solving skills, alcohol abuse, depression, illicit drug use, intimate partner violence, suicide attempts, reduced life expectancy, homelessness, and future re-victimization [17] [18] [19] [20] [21].

Studies have also documented what predicts adolescent fear of violence: younger age, being female (except for school-related fears) [22], minority status, low income, low education, being a resident of an urban environment [3] [10], the experience of community incivility [23] [24] and, in some cases, having been 
victimized in the past [25] [26]. Of the few studies specifically addressing outcomes related to the fear of violence, it has been shown that youth who fear being victimized by crime may take defensive actions to feel protected [26] [27] [28] and can experience spatial and social isolation and marginalization [29].

Although there are few studies examining the outcomes of fear of violence among adolescents separately from exposure to violence, we drew from related studies in the adult population and those examining child/adolescent exposures to violence to hypothesize possible associated problems. Garofalo [28] suggests that fear of crime has broad social consequences, such as distrust and alienation from social life [30]. Fear of crime has been shown to be higher among adults who report fewer prosocial attitudes [31] and evidence suggests that exposure to violence decreases prosocial skills among children [21]. Youth who fear being hurt by violence may cope by avoiding the people or places (e.g. school) that scare them [30] [32] and may also be reluctant to report these problems [33]. Socially withdrawn children often feel and think poorly of themselves, possibly leading to peer rejection and victimization by peers [34]. Stafford, Chandola, and Marmot [35] have found that, among adults, the curtailment of social activities is one pathway linking fear of crime to mental and physical health. Among adults, neighborhood disadvantage, disorder, and fear of crime and violence have been found to decrease physical functioning, lower ratings of self-reported health, and increase the occurrence of chronic conditions [36]. Among children, perceptions of neighborhood safety have been linked to their levels of physical activity, and subsequently, their physical health [37]. Based on our review, we hypothesize that adolescent fear of violence will be associated with increases withdrawn symptoms and social problems and decreases in prosociality and self-rated health.

\subsection{Family Support, Fear of Violence, and the Stress Process Model}

Family support systems may be a critical resource for youth who fear violence because youth have underdeveloped cognitive and coping abilities at hand to successfully adapt to stressful events on their own [38] [39] [40] [41]. In a national study of Canadian youth, Sacco and Nakhaie [42] found that positive parenting and mother's support were important predictors for youth's perception of safety at school and going to and from school. Studies of youth resilience consistently show that children and adolescents who have positive family support are more likely to meet numerous developmental tasks including academic and social competence, and have better psychosocial functioning [43] [44] [45] [46].

As suggested by the Stress Process Model [14] [47] [48], fear of violence is a stressor that may be moderated by social support which would then diminish the negative effects that fear of violence has on various health outcomes. Some research suggests that the mere perception of available familial support may be just as effective as the actual receipt of support when dealing with stress [49]. Given that supportive and positive family relationships are associated with fewer prob- 
lems resulting from childhood victimization [50], exposure to domestic violence [51], and exposure to community violence [52], we contend that positive family support may also moderate the relationship between fear of violence and adolescent outcomes.

\subsection{Gender Differences in Adolescent Outcomes}

Many stressful events do not occur precipitately, however, they can be traced back to social structures and an individuals' location within them (i.e. gender) [47]. As Aneshensel [53] and Horwitz [54] have suggested, we believe that gender is associated with a broad range of health and well-being outcomes and that males and females may respond to the same stressors in different ways. In general, research suggests that girls are more likely to respond to stressors with internalizing problems such as anxiety, depression, and social withdrawal and boys are more likely to respond to stressors with externalizing problems such as anger, behavioral problems, and aggression [55] [56]. For example, consistent with previous research [57], Keyes [58] examined emotional well-being, perceived positive feelings, and positive functioning in life. He reported that females tend to experience a higher rate of depression when compared to males, which may be an antecedent of social problems and withdrawal. Research exists that coping skills may be a learned behavior from others within an individuals' social sphere (i.e. family and friends) to cope with perceived stressful events (i.e. fear of violence, victimization) [47]. Nevertheless, it is unclear how perceived social and familial support vary by gender, such as whether females report more perceived support than males, or if no difference exists [49] [59] [60]. In addition, family support may be more a critical resource for girls than boys when dealing with stressors [49] [61] [62].

\subsection{The Present Study and Research Questions}

Scholars have recently emphasized a need in social science research to rely less on dichotomous diagnostic categorizations of individuals [53], to include multiple, continuous symptom scales in analyses [54], and to investigate social well-being alongside psychological and physical well-being [63]. Based on the above review, we hypothesize that, after controlling for several demographic factors and exposure to violence, both fear of violence and family support will be associated with adolescent levels of prosociality, social problems, withdrawn symptoms, and self-rated physical health (e.g. multiple, continuous symptoms scales) in main effects models. Our study assesses several dimensions of well-being, including social (i.e. prosociality), psychological (i.e. withdrawn symptoms), and physical (i.e. self-rated health). We also test whether family support moderates the effect of fear of violence on adolescent levels of prosociality, social problems, withdrawn symptoms, and self-rated physical health (i.e. a Stress Process model). Finally, we test models for males and females separately to identify gender-differentiated outcomes.

Thus, we test the following research questions in our study: 
RQ 1: Is fear of violence associated with increases in withdrawn symptoms and social problems and decreases prosociality and self-rated health, after controlling for exposure to violence and demographic characteristics?

RQ 2: Is positive family support associated with decreases in withdrawn symptoms and social problems and increases in prosociality and self-rated health, after controlling for all other factors.

RQ 3: Are the relationships between fear of violence and adolescent outcomes moderated by family support (i.e. a Stress Process model)?

RQ 4: Do the relationships between fear of violence, family support, and adolescent outcomes vary by gender, after controlling for exposure to violence and other demographic characteristics?

\section{Methods}

\subsection{Data and Sample Characteristics}

Data for our analyses come from the Longitudinal Cohort Study of the Project on Human Development in Chicago Neighborhoods (PHDCN), a large interdisciplinary study that focused on how neighborhood, family, and individual factors affect the development of both prosocial and antisocial behavior in a sample of children and adolescents [64] [65]. The PHDCN created a neighborhood cluster by collapsing 847 census tracts located in the city of Chicago to form 343 neighborhood clusters, hereinafter referred to as NCs [64] [65]. While creating each neighborhood cluster, the researchers ensured that each cluster was ecologically meaningful, composed of geographically adjacent census tracts, and internally homogenous on key census indicators [64] [65]. Researchers adopted the target sample size of 50 completed interviews for each of the 80 sampled neighborhood clusters selected for the longitudinal cohort study [64] [65]. In this study, there are approximately 17 adolescents per neighborhood in each of the 80 neighborhood clusters, resulting in a random sample of 651 (48.7\%) males, and 686 (51.3\%) females.

We use the first wave of data obtained in 1995 from cohorts 12 and $15(\mathrm{~N}=$ 1517), because we are interested in the adolescent period and theory suggests that exposure to violence is particularly impactful on youth during these years. In addition, it is currently unclear the extent to which the fear of violence is related to adolescent outcomes after controlling for exposure to violence and we do not test for change over time in this study. Therefore, we conduct an exploratory analysis of these relationships using only Wave 1 of the data. Race data showed the presence of several numerically small racial/ethnic categories (e.g., Asian American, Native American). We excluded these racial/ethnic groups so that our sample included only Latino, Black, and White respondents and, additionally, we selected cases with complete data on the variables used in our analyses for inclusion in the sample, resulting in an analytic sample of $\mathrm{N}=1337$. The PHDCN is one of the largest longitudinal datasets and used in a vast amount of interdisciplinary studies that examine juvenile delinquency, substance 
abuse, violence, and collective efficacy. The dataset encourages understanding of the developmental pathways of both positive and negative human social behaviors [64]. Generally, sampled surveys examined individual level relations, whereas the PHDCN merges a cluster sample design which considers collective properties of neighborhood conditions [64]. The design of the PHDCN, along with the low attrition rate, extensive racial/ethnic composition, and ecologically meaningful neighborhood clusters [64], lends itself to continued use today. Demographic characteristics of the sample are reported in Table 1.

Table 1. Descriptive statistics for all variables in the analysis.

\begin{tabular}{|c|c|c|c|}
\hline Variable (code) & Frequency (\%) & Range & Mean (SD) \\
\hline \multicolumn{4}{|l|}{ Gender } \\
\hline Male (0) & $652(48.7 \%)$ & & \\
\hline Female (1) & $686(51.3 \%)$ & & \\
\hline \multicolumn{4}{|l|}{ Cohort } \\
\hline 12 years old (1) & $723(54.1 \%)$ & & \\
\hline 15 years old (2) & $614(45.9 \%)$ & & \\
\hline \multicolumn{4}{|l|}{ Racel Ethnicity } \\
\hline Latino $(0)$ & $630(47.1 \%)$ & & \\
\hline Black (1) & $513(38.3 \%)$ & & \\
\hline White (2) & $195(14.6 \%)$ & & \\
\hline Caregiver Education Level & & $1-5$ & $2.99(1.34)$ \\
\hline Less Than High School (1) & $260(19.4 \%)$ & & \\
\hline Some High School (2) & $278(20.8 \%)$ & & \\
\hline Finish High School (3) & $173(12.9 \%)$ & & \\
\hline Some More Than High School (4) & $472(35.3 \%)$ & & \\
\hline Bachelor's Degree or More (5) & $154(11.5 \%)$ & & \\
\hline Neighborhood SES & & $1-3$ & $1.86(0.76)$ \\
\hline Low (1) & $487(36.4 \%)$ & & \\
\hline Medium (2) & $549(41.0 \%)$ & & \\
\hline High (3) & $302(22.6 \%)$ & & \\
\hline Exposure to Violence & & $0-3$ & $1.22(0.76)$ \\
\hline Fear of Violence & & $0-4$ & $1.39(1.25)$ \\
\hline Family Support & & $1-5$ & $4.07(1.19)$ \\
\hline Prosocial Disposition & & $1-9$ & $6.68(2.29)$ \\
\hline Self-Rated Health & & $1-5$ & $3.75(0.99)$ \\
\hline Poor (1) & $11(0.8 \%)$ & & \\
\hline Fair (2) & $151(11.3 \%)$ & & \\
\hline Good (3) & $343(25.6 \%)$ & & \\
\hline Very Good (4) & $489(36.5 \%)$ & & \\
\hline Excellent (5) & $344(25.7 \%)$ & & \\
\hline Withdrawn $(C B C L)$ & & $0-10$ & $2.84(2.64)$ \\
\hline Social Problems $(C B C L)$ & & $0-10$ & $2.44(2.30)$ \\
\hline
\end{tabular}




\subsection{Measures}

Our dependent variables include prosociality, social problems, withdrawn symptoms, and physical health. Prosociality, operationalized as a willingness to help others, to be fair to others, and to be friendly to others, was derived from the Youth Self-Report (YSR) [66]. Youth rated themselves $(0=$ not true, $1=$ somewhat or sometimes true, 2 = very or often true) on six items: "I am willing to help others if they need help," "I can be pretty friendly," "I enjoy being with other people," "I like to help others," "I try to be fair to others," "I try to help other people when I can." Previous factor analysis [67] shows that the items hang together on one factor and it is a valid measure. In our study, the scale was reliable (Cronbach's Alpha $[C A]=0.77$ ) with scores ranging from 1 to 9 . Higher scores indicate more prosociality.

Both the Social Problems and Withdrawn Symptoms scales come from the Child Behavior Checklist (CBCL) [68]. Youth are rated by their parents $(0=$ not true, $1=$ somewhat or sometimes true, 2 = very or often true) on several items for each of nine primary subscales on the assessment. The CBCL is a standardized, reliable, valid, and widely used assessment in the social sciences [68]. The Social Problems scale includes 8 items: "Acts too young for age," "Clings to adults or too dependent," "Doesn't get along with other children," "Gets teased a lot," "Not liked by other kids," "Overweight," "Poorly coordinated or clumsy," "Prefers being with younger kids" $(\mathrm{CA}=0.62)$. In our sample, the scale had scores ranging from 0 - 10. Higher scores indicate more social problems. The Withdrawn Symptoms scale includes 9 items $(\mathrm{CA}=0.74)$ : "Would rather be alone than with others," "Refuses to talk," "Secretive, keeps things to self," "Shy or timid," "Stares blankly," "Sulks a lot," "Underactive, slow moving, or lacks energy," "Unhappy, sad, or depressed," "Withdrawn, doesn't get involved with others," with scores ranging from 0 to 10 . Higher scores indicate more withdrawn symptoms.

Physical health was measured with a single, self-reported item. Respondents were asked, "Would you say that in general your health is excellent, very good, good, fair, or poor?" Responses ranged from 1 to 5. Responses were reverse-coded so that higher scores indicate better self-rated health. A number of studies used this single-item measure in past research and found it to have good validity and reliability [69].

Family Support is measured with 4 items from the Provision of Social Relations [70] assessment ( $1=$ very true, $2=$ somewhat true, $3=$ not true): "No matter what happens, I know my family will always be there for me should I need them," "People in my family have confidence in me," "People in my family help me find solutions to my problems," "I know my family will always stand by me." Scores were recoded $1=$ not true, $2=$ somewhat true, and $3=$ very true so that higher scores indicated greater family support. In our sample, the scale was reliable $(\mathrm{CA}=0.64)$ with scores ranging from 1 to 5 .

Our primary independent variable, Fear of Violence, is measured with 4 items 
from the Exposure to Violence assessment [71]. Youth responded yes $(=1)$ or no $(=0)$ to the following questions: "Are you afraid you might be hurt by violence in your neighborhood?," "Are you afraid you might be hurt in front of your apartment building or house?," "Are you afraid you might be hurt in your apartment building or house?," "Are you afraid you might be hurt by violence at school or work?" Responses to these items were summed, creating a count variable, and ranged from 0 to 4 . Higher scores indicate a greater fear of violence. Researchers often use context-specific measures to create scales to capture an overall trait in an analysis [72]. In order to establish construct validity, the gold standard is to assess convergent validation [72]. Bartlett's test of sphericity was significant $\left(\chi^{2}\right.$ $(6)=418.31, p<0.001)$. The Kaiser-Meyer-Olkin measure of sampling adequacy indicated that the strength of the relationships among variables within the Fear of Violence variable was adequate $(\mathrm{KMO}=0.702)$, above the commonly accepted value of 0.6 , allowing us to proceed with the analysis.

We included several control variables in our analysis: exposure to violence, gender, race, cohort, parent's education, neighborhood socioeconomic status (SES). Exposure to violence is a sum of three items from the Exposure to Violence assessment [71]. Youth responded yes $(=1)$ or no $(=0)$ to the following questions: "Have you ever seen someone shoved, kicked, or punched?", "Have you ever seen someone attacked with a knife?", "Have you ever seen someone shot?" Gender and cohort were dummy coded, with male and Cohort 12 as the reference group. Race was dummy coded into two variables (Black and Latino) with White as the reference group. Parent's education, neighborhood SES, and exposure to violence were all treated as interval level measures in the analyses. Descriptive statistics and coding for all variables in our models are presented in Table 1.

\subsection{Analytic Strategy}

We first calculated descriptive statistics (Table 1) and then estimated several mixed-effect regressions for each of our dependent variables, using Maximum Likelihood estimation, and which takes into account nesting by neighborhood. We assessed whether the relationship between fear of violence and each of the outcome variables was moderated by family support (Table 2). We also conducted mixed-effect, multi-level regressions for "males only" (Table 3) and for "females only" (Table 4) samples. We run separate analyses for boys and girls to assess whether relationships between our independent variables and dependents vary by gender. In addition, we conducted equality of regression coefficient tests to confirm gender differences [73]. Given that the participants are nested within neighborhoods, we use the xtmixed routine in STATA 13 [74]. We estimate mixed-effect, multi-level models because standard regression estimates individual error and misses group-level error, leading to an underestimate of standard errors, and increasing the likelihood of Type II error. Preliminary analyses showed that there was little variation across neighborhoods for all dependent va- 
riables. Thus, our models placed all independent variables at level 1 and estimated a random intercept equation. This model takes nesting into account, but does not estimate how the independent variables predict our outcome variables across neighborhoods (i.e., random slope equations).

Table 2. Combined final models for all outcomes, total sample $(\mathrm{N}=1337)$.

\begin{tabular}{|c|c|c|c|c|}
\hline & Prosociality & Self-Rated Health & $\begin{array}{l}\text { Withdrawn } \\
\text { Symptoms }\end{array}$ & $\begin{array}{c}\text { Social } \\
\text { Problems }\end{array}$ \\
\hline Female & $0.73(0.12)^{\star \star \star *}$ & $-0.03(0.05)$ & $0.06(0.14)$ & $-0.16(0.12)$ \\
\hline Cohort & $-0.06(0.12)$ & $-0.10(0.05)+$ & $0.42(0.14)^{* *}$ & $-0.50(0.13)^{\star * *}$ \\
\hline Black & $-0.41(0.19)^{\star}$ & $0.00(0.08)$ & $0.22(0.23)$ & $0.30(0.20)$ \\
\hline Latino & $-0.01(0.20)$ & $-0.24(0.09)^{\star \star}$ & $0.98(0.23)^{\star * *}$ & $0.16(0.20)$ \\
\hline $\begin{array}{c}\text { Parent's } \\
\text { Education }\end{array}$ & $-0.01(0.05)$ & $0.04(0.02)+$ & $-0.17(0.06)^{\star *}$ & $-0.07(0.05)$ \\
\hline $\begin{array}{c}\text { Neighborhood } \\
\text { SES }\end{array}$ & $0.15(0.09)+$ & $0.01(0.04)$ & $-0.11(0.10)$ & $-0.02(0.09)$ \\
\hline $\begin{array}{l}\text { Exposure } \\
\text { to Violence }\end{array}$ & $0.04(0.08)$ & $0.04(0.04)$ & $0.06(0.10)$ & $0.08(0.09)$ \\
\hline Fear of Violence & $-0.06(0.05)$ & $-0.04(0.02)^{*}$ & $0.09(0.06)$ & $0.26(0.05)^{\star * *}$ \\
\hline Family Support & $0.53(0.05)^{* * *}$ & $0.16(0.02)^{\star * *}$ & $-0.28(0.06)^{\star * *}$ & $-0.20(0.05)^{* * *}$ \\
\hline Constant & $4.14(0.39)^{\star \star \star}$ & $3.13(0.17)^{\star \star *}$ & $3.70(0.46)^{\star * *}$ & $3.15(0.41)^{\star * *}$ \\
\hline $\begin{array}{l}\text { Wald-Chi } \\
\text { Square }\end{array}$ & $162.87^{\star * *}$ & $116.57^{\star * *}$ & $123.85^{\star * \star}$ & $75.29^{\star \star *}$ \\
\hline
\end{tabular}

$+\mathrm{p}<0.10,{ }^{*} \mathrm{p}<0.05,{ }^{* *} \mathrm{p}<0.01,{ }^{* * *} \mathrm{p}<0.001$.

Table 3. Combined final models for all outcomes, male sample only $(\mathrm{N}=651)$.

\begin{tabular}{|c|c|c|c|c|}
\hline & Prosociality & $\begin{array}{l}\text { Self-Rated } \\
\text { Health }\end{array}$ & $\begin{array}{l}\text { Withdrawn } \\
\text { Symptoms }\end{array}$ & $\begin{array}{c}\text { Social } \\
\text { Problems }\end{array}$ \\
\hline Cohort & $-0.19(0.18)$ & $-0.01(0.08)$ & $0.35(0.20)+$ & $-0.61(0.18)^{\star \star * *}$ \\
\hline Black & $-0.56(0.29)^{\star}$ & $0.03(0.12)$ & $0.07(0.32)$ & $0.13(0.29)$ \\
\hline Latino & $-0.42(0.29)$ & $-0.23(0.12)+$ & $0.55(0.33)+$ & $-0.02(0.30)$ \\
\hline $\begin{array}{l}\text { Parent's } \\
\text { Education }\end{array}$ & $-0.10(0.08)$ & $0.08(0.03)^{\star}$ & $-0.25(0.09)^{\star \star}$ & $-0.07(0.08)$ \\
\hline $\begin{array}{c}\text { Neighborhood } \\
\text { SES }\end{array}$ & $0.27(0.13)^{*}$ & $0.04(0.06)$ & $0.01(0.15)$ & $-0.03(0.13)$ \\
\hline $\begin{array}{c}\text { Exposure } \\
\text { to Violence }\end{array}$ & $0.10(0.12)$ & $-0.00(0.05)$ & $0.19(0.14)$ & $-0.02(0.13)$ \\
\hline Fear of Violence & $-0.12(0.08)$ & $-0.01(0.03)$ & $0.17(0.09)^{\star}$ & $0.37(0.08)^{\star * *}$ \\
\hline Family Support & $0.71(0.08)^{\star * *}$ & $0.14(0.03)^{\star * *}$ & $-0.23(0.09)^{\star *}$ & $-0.18(0.08)^{\star}$ \\
\hline Constant & $3.74(0.58)^{\star * *}$ & $2.99(0.25)^{\star * *}$ & $3.52(0.65)^{\star * *}$ & $3.29(0.59)^{* * *}$ \\
\hline $\begin{array}{l}\text { Wald-Chi } \\
\text { Square }\end{array}$ & $103.19^{* * *}$ & $59.78^{\star * *}$ & $54.36^{\star * *}$ & $48.88^{\star \star \star}$ \\
\hline
\end{tabular}

$+\mathrm{p}<0.10,{ }^{*} \mathrm{p}<0.05,{ }^{* *} \mathrm{p}<0.01,{ }^{* * *} \mathrm{p}<0.001$. 
Table 4. Combined final models for all outcomes, female sample only $(\mathrm{N}=686)$.

\begin{tabular}{ccccc}
\hline & Prosociality & $\begin{array}{c}\text { Self-Rated } \\
\text { Health }\end{array}$ & $\begin{array}{c}\text { Withdrawn } \\
\text { Symptoms }\end{array}$ & $\begin{array}{c}\text { Social } \\
\text { Problems }\end{array}$ \\
\hline Cohort & $0.04(0.16)$ & $-0.20(0.08)^{* *}$ & $0.48(0.20)^{*}$ & $-0.41(0.18)^{*}$ \\
Black & $-0.18(0.26)$ & $-0.02(0.12)$ & $0.43(0.32)$ & $0.45(0.27)+$ \\
Latino & $0.40(0.26)$ & $-0.22(0.12)+$ & $1.40(0.32)^{* * *}$ & $0.35(0.28)$ \\
$\begin{array}{c}\text { Parent's } \\
\text { Education }\end{array}$ & $0.05(0.07)$ & $-0.01(0.03)$ & $-0.11(0.08)$ & $-0.06(0.07)$ \\
$\begin{array}{c}\text { Neighborhood } \\
\text { SES }\end{array}$ & $0.04(0.11)$ & $0.01(0.06)$ & $-0.22(0.14)$ & $0.00(0.12)$ \\
Exposure to \\
Violence
\end{tabular}

\section{Results}

\subsection{Descriptive Findings}

We report descriptive statistics for the sample in Table 1 . Slightly more than half of the sample was female (51\%), while $47 \%$ of the adolescents in the sample were Latino, $38 \%$ were Black, and $15 \%$ were White. In terms of educational attainment for the primary caregiver and the social class of neighborhood where the respondents live, about $53 \%$ had a high school education or less, about a third lived in low income neighborhoods, and almost $23 \%$ lived in high income neighborhoods. Respondents had some exposure to and fear of violence, with a mean exposure of $1.22(\mathrm{SD}=0.76)$ and a mean fear of $1.39(\mathrm{SD}=1.25)$. They also reported that their family was quite supportive with a mean of 4.07 ( $\mathrm{SD}=$ 1.19) on a five-point scale. Finally, for our outcome measures, adolescents in the study scored high on prosocial disposition (Mean $=6.68, \mathrm{SD}=2.29$ ), rated their health as mostly good or excellent (Mean $=3.75, \mathrm{SD}=0.99$ ), and scored low on the $\mathrm{CBCL}$ Withdrawal (Mean $=2.84, \mathrm{SD}=2.64$ ) and Social Problem (Mean = $2.44, \mathrm{SD}=2.30)$ subscales. The majority of our bivariate correlations were weak $(<0.30)$, but significant at $\mathrm{p}<0.01$, and we found no evidence of multicollinearity. Specific to one of our concerns, exposure to violence and fear of violence are correlated at $0.10(\mathrm{p}<0.01)$, giving us some confidence that exposure and fear are related, but separate concepts.

\subsection{Mixed-Effect, Multi-Level Regression Models}

We report findings from the mixed-effect, multi-level regressions in three tables: the full model (Table 2), the males only model (Table 3), and the females only 
model (Table 4). We tested each model for occurrences of moderation in the relationship between fear of violence, family support, and each outcome. Similar to Sousa et al. 2011, we found only direct effects of family support, but no evidence of statistical moderation for any outcome or for any model. We discuss the main effects models in turn for each dependent variable, beginning with the full model.

In the full model (Table 2$)$ for prosociality, being female $(\beta=0.73, \mathrm{p}<0.001)$ and having family support $(\beta=0.53, \mathrm{p}<0.001)$ significantly predicted higher levels of prosociality, while being black $(\beta=-0.41, \mathrm{p}<0.05)$ predicted significantly lower levels of prosociality, after controlling for all other factors. Neighborhood SES approached significance $(\beta=0.15, \mathrm{p}<0.10)$ predicting higher levels of prosociality. In the full model for self-rated health, being Latino ( $\beta=$ $-0.024, \mathrm{p}<0.01)$ and fear of violence $(\beta=-0.04, \mathrm{p}<0.05)$ was related to lower self-rated health. In contrast, family support $(\beta=0.16, \mathrm{p}<0.001)$ predicted significantly higher levels of self-rated health. Cohort $(\beta=-0.10, \mathrm{p}<0.10)$ and parental education $(\beta=0.04, \mathrm{p}<0.10)$ approached significance, with youth in Cohort 15 reporting worse health and higher parental education predicting higher levels of health. In the full model for withdrawn symptoms, being in Cohort 15 $(\beta=0.42, \mathrm{p}<0.01)$ and being Latino $(\beta=0.98, \mathrm{p}<0.001)$ predicted significantly higher levels on this outcome, while higher parental education $(\beta=-0.17, \mathrm{p}<$ $0.01)$ and family support $(\beta=-0.28, \mathrm{p}<0.001)$ was associated with significantly lower levels of withdrawn symptoms. In the full model for social problems, being older $(\beta=-0.50, \mathrm{p}<0.001)$ and having family support $(\beta=-0.20, \mathrm{p}<0.001)$ predicted significantly lower levels of social problems and fear of violence $(\beta=$ $0.26, \mathrm{p}<0.001)$ predicted significantly higher levels of social problems, after controlling for all other factors.

In the males only model (Table 3 ) for prosociality, being black $(\beta=-0.56, \mathrm{p}<$ $0.05)$ predicted significantly lower levels of prosociality and neighborhood SES $(\beta=0.27, \mathrm{p}<0.05)$ and family support $(\beta=0.71, \mathrm{p}<0.001)$ predicted higher levels of prosociality, after controlling for all other factors. In the males only model for self-rated health, parental education $(\beta=0.08, \mathrm{p}<0.05)$ and family support $(\beta=0.14, \mathrm{p}<0.001)$ predicted significantly higher levels of self-rated health, after controlling for all other factors. Being Latino approached significance $(\beta=$ $-0.23, \mathrm{p}<0.10)$, predicting lower levels of self-rated health. In the males only model for withdrawn symptoms, parental education $(\beta=-0.25, \mathrm{p}<0.01)$ and family support $(\beta=-0.23, \mathrm{p}<0.01)$ predicted significantly lower levels of withdrawn symptoms and fear of violence $(\beta=0.17, \mathrm{p}<0.05)$ predicted significantly higher levels of withdrawn symptoms. Being older $(\beta=0.35, \mathrm{p}<0.10)$ and being Latino $(\beta=0.55, \mathrm{p}<0.10)$ approached significance, predicting significantly higher levels of withdrawn symptoms. In the males only model for social problems, being older $(\beta=-0.61, \mathrm{p}<0.001)$ and family support $(\beta=-0.18, \mathrm{p}<0.05)$ predicted significantly lower levels of social problems and fear of violence $(\beta=$ $0.37, \mathrm{p}<0.001)$ predicted significantly higher levels of social problems. 
In the females only model (Table 4 ) for prosociality, family support ( $\beta=0.37$, $\mathrm{p}<0.001)$ predicted significantly higher levels of prosociality, after controlling for all other factors. In the females only model for self-rated health, being older $(\beta=-0.20, \mathrm{p}<0.01)$ and fear of violence $(\beta=-0.07, \mathrm{p}<0.05)$ predicted significantly lower levels of self-rated health and family support $(\beta=0.17, \mathrm{p}<0.001)$ predicted significantly higher levels of self-rated health. Being Latino approached significance $(\beta=-0.22, \mathrm{p}<0.10)$, predicting significantly lower levels of self-rated health. In the females only model for withdrawn symptoms, being older $(\beta=0.48, \mathrm{p}<0.05)$ and being Latino $(\beta=1.40, \mathrm{p}<0.001)$ predicted significantly higher levels of withdrawn symptoms and family support $(\beta=-0.32, \mathrm{p}<$ $0.001)$ predicted significantly lower levels of withdrawn symptoms. In the females only model for social problems, being older $(\beta=-0.41, \mathrm{p}<0.05)$ and family support $(\beta=-0.20, \mathrm{p}<0.01)$ predicted significantly lower levels of social problems and fear of violence $(\beta=0.17, \mathrm{p}<0.05)$ predicted significantly higher levels of social problems, after controlling for all other factors. Being black approached significance $(\beta=0.45, \mathrm{p}<0.10)$, predicting higher levels of social problems.

After comparing models separately for males and females, we conducted tests for the equality of regression coefficients to confirm whether the gender differences were significant using the method outlined by Paternoster and colleagues [73] and testing significance at $\mathrm{p}<0.05$. We found that being Latino was more likely to decrease prosociality for boys and more likely to increase prosociality for girls (Equivalence test $=-2.10$ ). In addition, family support had a significantly more positive effect on prosociality for boys than girls. For self-rated health, the equivalence test $(=2.00)$ confirmed that parent's education was positively associated for boys' health, but not girls' health. Using Paternoster's method, we were not able to confirm any significant gender differences on the effects of our variables on the outcome withdrawal symptoms. Finally, although the fear of violence was significantly related to an increase in social problems for both boys and girls, the effect was significantly stronger for boys (Equivalence test $=1.97)$.

\section{Discussion and Implications}

The purpose of this study was to investigate how fear of violence and family support affect adolescents' social, psychological, and physical well-being, after controlling for exposure to violence and a range of demographic factors. In our study, we found that fear of violence was associated with an increase in social problems (especially for boys) and a decrease in self-rated health (RQ 1). In addition, we found that family support was associated with increases in prosociality and self-rated health and decreases in withdrawn symptoms and social problems (RQ 2). Unexpectedly, we found no support for a Stress Process model (RQ 3). Finally, we did find evidence for multiple gender differences in the relationships between fear of violence and our outcome variables (RQ 4). 
Overall, we find that family support is the most robust predictor across all outcomes and in all three analyses (full, males only, females only). Family support is a compensatory factor because in main effects models, it is broadly beneficial to all youth, regardless of group membership [75]. For all adolescents in our sample, regardless of gender, race, SES, or exposure to or fear of violence, family support is key to increasing prosociality and self-rated health, and key to decreasing withdrawn symptoms and social problems. The implications of these findings propose that we must increase the accessibility of resources that promote supportive and healthy relationships within families. These types of family relationships increase the likelihood that young people will thrive and be successful in their transitions to adulthood [58] [76].

Fear of violence is a risk factor for adolescents in our sample because it is associated with decreases in self-rated health and increases in social problems (especially for boys). When comparing our models separately, we found that the fear of violence was associated with an increase in withdrawn symptoms for boys only, but our test of the equality of regression coefficients did not confirm this difference. Our measure of exposure to violence was not significant for any outcome in any model. This is contrary to what we expected, given past research finds strong support for the effects of exposure to violence on well-being. On the one hand, non-significance may be due to the measure's construction, since we used an additive measure of four binary fear of violence questions, although the measure did meet all criteria for convergent validity. However, the fact that exposure to violence was not significant in our models that included fear of violence lends support to the theory that the fear of violence is conceptually distinct from the exposure to violence. Although fear of violence and exposure to violence are significantly correlated, the small correlation coefficient $(r=0.10)$ supports the conclusion that they are related, but conceptually distinct.

Yearwood [77] suggests that professionals and parents in children's lives help them to manage their fears about actual or potential violence by allowing children to talk about what is going on, providing an outlet for their emotions, and to spend more time with children, providing reassurance that the feelings they are experiencing are normal. For example, in a qualitative study of twenty adolescents living in public-subsidized high rise building in Chicago, teens suggested that adults in their lives openly discuss life's dangers with them and ensure that they know that adults are available to protect them [78]. Promoting supportive relationships between parents and children may strengthen the family dynamic and allow youth to feel more comfortable discussing issues such as their fear of victimization and support their internal struggle to cope with that fear [79].

Our research confirms some of the findings from the few studies that specifically address adolescent outcomes associated with the fear of violence. Specifically, the fear of violence was associated with social problems for both boys and girls. Our study adds that, in our sample, the effect was stronger for boys' 
social problems. We found it useful to examine gender-specific models for our outcomes, supporting Aneshensel's [53] and Horwitz's [54] observation that males and females respond to stressors in different ways. This relationship was evident in our adolescent sample. For example, parent's education was positively associated with boys' self-rated health, but not for girls. These gender-specific models also revealed patterns that differed by race. For example, being Latino was more likely to decrease prosociality for boys and more likely to increase prosociality for girls. Future studies should continue to explore how gender and race, and their intersections, lead to differential outcomes for adolescents.

Our study was enriched by the inclusion of multiple, continuous symptomatology scales, as suggested by Horwitz [54] and Keyes [63]. By examining physical health, psychological health, and social well-being outcomes on a continuum and as a group, we were able to describe in better detail the positive effects of family support and the negative effects of the fear of violence. Future studies should continue to assess adolescent well-being from a range of perspectives, taking a more holistic and systematic approach to understanding risks to their health.

Research following from the present study may have implications for the promotion of methods that may contribute in efforts to influence adolescent social, psychological, and physical well-being as a result of exposure to violence and associated trauma. This is important in today's climate where increasing incidents of neighborhood violence, bullying, mass shootings at schools, festivals, churches and mosques, shopping centers, and public venues take place. Understanding how resilience operates through coping strategies and support systems for adolescents that experience exposure to violence may decrease long-term negative effects. This may encourage increased social, psychological, and physical well-being trajectories.

\section{Strengths and Limitations}

Our study has several strengths, including one of the largest studies of U.S. children living in urban neighborhoods, reliable and valid scales measuring key variables, and a large percentage of African American and Latino children in our sample. Nevertheless, all of our findings need to be considered within the context of the study's limitations. First, our data were collected in Chicago, which limits the generalizability of our findings to other urban areas, as well as, to suburban and rural youth. However, the original investigators selected Chicago because it has been extensively studied and did reflect many of the urban issues important to sociological theories of crime and delinquency [64]. Second, the data used in our study were collected in the mid-90's which may limit the generalizability of our findings about youth twenty years later. Finally, as with all cross-sectional studies, we cannot make causal attributions to the relationships between our independent and dependent variables. 


\section{Conflicts of Interest}

The authors declare no conflicts of interest regarding the publication of this paper.

\section{References}

[1] Hall, G.S. (1897) A Study of Fears. The American Journal of Psychology, 8, 147-249. https://doi.org/10.2307/1410940

[2] Adler, J. (1994) Kids Growing Up Scared. Newsweek, January 10, 43-50.

[3] Burnham, J.J. (2005) Fears of Children in the United States: An Examination of the American Fear Survey Schedule with 20 New Contemporary Fear Items. Measurement and Evaluation in Counseling and Development, 38, 78.

https://doi.org/10.1080/07481756.2005.11909770

[4] Burnham, J.J. (2009) Contemporary Fears of Children and Adolescents: Coping and Resiliency in the 21st Century. Journal of Counseling Development, 87, 28-35. https://doi.org/10.1002/j.1556-6678.2009.tb00546.x

[5] Finkelhor, D. (2008) Childhood Victimization: Violence, Crime, and Abuse in the Lives of Young People. Oxford University Press, New York. https://doi.org/10.1093/acprof:oso/9780195342857.001.0001

[6] Finkelhor, D., Turner, H., Ormrod, R., Hamby, S. and Kracke, K. (2009) National Survey of Children's Exposure to Violence. Juvenile Justice Bulletin, 1-11.

[7] Snyder, H.N. and Sickmund, M. (2006) Juvenile Offenders and Victims: 2006 National Report. Office of Juvenile Justice and Delinquency Prevention, Washington DC.

[8] Cockburn, T. (2008) Fears of Violence among English Young People: Disintegration Theory and British Social Policy. New Directions for Youth Development, 2008, 75-91. https://doi.org/10.1002/yd.274

[9] Alvarez, A. and Bachman, R. (1997) Predicting the Fear of Assault at School and While Going to and from School in an Adolescent Population. Violence and Victims, 12, 69-86. https://doi.org/10.1891/0886-6708.12.1.69

[10] Ferraro, K.F. (1995) Fear of Crime: Interpreting Victimization Risk. SUNY Press, Albany.

[11] Warr, M. (2000) Fear of Crime in the United States: Avenues for Research and Policy. Criminal Justice, 4, 451-489.

[12] Buka, S.L., Stichick, T.L., Birdthistle, I. and Felton, F.J. (2001) Youth Exposure to Violence: Prevalence, Risks, and Consequences. American Journal of Orthopsychiatry, 71, 298-310. https://doi.org/10.1037/0002-9432.71.3.298

[13] Graham-Bermann, S.A, DeVoe, E.R., Mattis, J.S., Lynch, S. and Thomas, S.A. (2006) Ecological Predictors of Traumatic Stress Symptoms in Caucasian and Ethnic Minority Children Exposed to Intimate Partner Violence. Violence against Women, 12, 663-692. https://doi.org/10.1177/1077801206290216

[14] Aneshensel, C.S. and Sucoff, C.A. (2002) Neighborhood and Adolescent Health: Structure and Experience. In: Maney, A. and Ramos, J., Eds., Socioeconomic Conditions, Stress, and Mental Disorders. Toward a New Synthesis of Research and Public Policy, NIMH, Washington DC, 41-77.

[15] Appleyard, K., Egeland, B., van Dulmen, M.H.M. and Sroufe, L.A. (2005) When More Is Not Better: The Role of Cumulative Risk in Child Behavior Outcomes. 
Journal of Child Psychology and Psychiatry, 46, 235-245.

https://doi.org/10.1111/j.1469-7610.2004.00351.x

[16] Bourassa, C. (2007) Co-Occurrence of Interparental Violence and Child Physical Abuse and Its Effect on the Adolescents' Behavior. Journal of Family Violence, 22, 691-701. https://doi.org/10.1007/s10896-007-9117-8

[17] Zimmerman, G.M. and Messner, S.F. (2013) Individual, Family Background, and Contextual Explanations of Racial and Ethnic Disparities in Youths' Exposure to Violence. American Journal of Public Health, 103, 435-442. https://doi.org/10.2105/AJPH.2012.300931

[18] Kennedy, A.C. (2008) An Ecological Approach to Examining Cumulative Violence Exposure among Urban, African American Adolescents. Child and Adolescent Social Work Journal, 25, 25-41. https://doi.org/10.1007/s10560-007-0110-0

[19] Wilkins, N., Tsao, B., Hertz, M., Davis, R. and Klevens, J. (2014) Connecting the Dots: An Overview of the Links among Multiple Forms of Violence. National Center for Injury Prevention and Control, Centers for Disease Control and Prevention, Atlanta, Prevention Institute, Oakland.

[20] Margolin, G. and Vickerman, K.A. (2011) Posttraumatic Stress in Children and Adolescents Exposed to Family Violence: I. Overview and Issues. Couple and Family Psychology: Research and Practice, 38, 63-73. https://doi.org/10.1037/2160-4096.1.S.63

[21] Holmes, M.R., Voith, L.A. and Gromoske, A.N. (2015) Lasting Effect of Intimate Partner Violence Exposure during Preschool on Aggressive Behavior and Prosocial Skills. Journal of Interpersonal Violence, 30, 1651-1670. https://doi.org/10.1177/0886260514552441

[22] Burnham, J.J., Schaefer, B.A. and Giesen, J. (2006) An Empirical Taxonomy of Youths' Fears: Cluster Analysis of the American Fear Survey Schedule. Psychology in the Schools, 43, 673-683. https://doi.org/10.1002/pits.20178

[23] May, D.C. and Dunaway, R.G. (2000) Predictors of Fear of Criminal Victimization at School among Adolescents. Sociological Spectrum, 20, 149-168. https://doi.org/10.1080/027321700279938

[24] LaGrange, R.L., Ferraro, K.F. and Supancic, M. (1992) Perceived Risk and Fear of Crime: Role of Social and Physical Incivilities. Journal of Research in Crime and Delinquency, 29, 311-334. https://doi.org/10.1177/0022427892029003004

[25] Grubb, J.A. and Bouffard, L.A. (2015) The Influence of Direct and Indirect Juvenile Victimization Experiences on Adult Victimization and Fear of Crime. Journal of Interpersonal Violence, 30, 3151-3173. https://doi.org/10.1177/0886260514554423

[26] Melde, C., Taylor, T.J. and Esbensen, F. (2009) "I Got Your Back": An Examination of the Protective Function of Gang Membership in Adolescence. Criminology, 47, 565-594. https://doi.org/10.1111/j.1745-9125.2009.00148.x

[27] Williams, J.S., Singh, B.K. and Singh, B.B. (1994) Urban Youth, Fear of Crime, and Resulting Defensive Actions. Adolescence, 29, 323.

[28] Garofalo, J. (1981) The Fear of Crime: Causes and Consequences. The Journal of Criminal Law and Criminology, 72, 839-857. https://doi.org/10.2307/1143018

[29] Pain, R. (2000) Place, Social Relations and the Fear of Crime: A Review. Progress in Human Geography, 24, 365-387. https://doi.org/10.1191/030913200701540474

[30] Harding, D.J. (2010) Living the Drama: Community, Conflict, and Culture among Inner-City Boys. University of Chicago Press, Chicago. 
https://doi.org/10.7208/chicago/9780226316666.001.0001

[31] Fletcher, G. and Allen, J. (2002) Perceptions of and Concern about Crime in England and Wales. In: Simmons, J. and Dodd, T., Eds., Crime in England and Wales 2002/2003, Office of National Statistics, London, 127-153.

[32] Brown, B. and Benedict, W.R. (2004) Bullets, Blades, and Being Afraid in Hispanic High Schools: An Exploratory Study of the Presence of Weapons and Fear of Weapon-Associated Victimization among High School Students in a Border Town. Crime and Delinquency, 50, 372-394. https://doi.org/10.1177/0011128703254916

[33] MacDonald, R. (1997) Youth, the "Underclass" and Social Exclusion. Psychology Press, New York.

[34] Rubin, K.H., Coplan, R.J. and Bowker, J.C. (2009) Social Withdrawal in Childhood. Annual Review of Psychology, 60, 141-171. https://doi.org/10.1146/annurev.psych.60.110707.163642

[35] Stafford, M., Chandola, T. and Marmot, M. (2007) Association between Fear of Crime and Mental Health and Physical Functioning. American Journal of Public Health, 97, 2076-2081. https://doi.org/10.2105/AJPH.2006.097154

[36] Ross, C.E. and Mirowsky, J. (2001) Neighborhood Disadvantage, Disorder, and Health. Journal of Health and Social Behavior, 42, 258-276. https://doi.org/10.2307/3090214

[37] Carver, A., Timperio, A. and Crawford, D. (2008) Perceptions of Neighborhood Safety and Physical Activity among Youth: The CLAN Study. Journal of Physical Activity and Health, 5, 430. https://doi.org/10.1123/jpah.5.3.430

[38] Moses, A. (1999) Exposure to Violence, Depression, and Hostility in a Sample of Inner City High School Youth. Journal of Adolescence, 22, 21-32. https://doi.org/10.1006/jado.1998.0198

[39] Overstreet, S. and Dempsey, M. (1999) Availability of Family Support as a Moderator of Exposure to Community Violence. Journal of Clinical Child Psychology, 28, 151-159. https://doi.org/10.1207/s15374424jccp2802_3

[40] Graham-Bermann, S.A., Lynch, S., Banyard, V., DeVoe, E.R. and Halabu, H. (2007) Community-Based Intervention for Children Exposed to Intimate Partner Violence: An Efficacy Trial. Journal of Consulting and Clinical Psychology, 75, 199-209. https://doi.org/10.1037/0022-006X.75.2.199

[41] Youngstrom, E., Weist, M.D. and Albus, K.E. (2003) Exploring Violence Exposure, Stress, Protective Factors and Behavioral Problems among Inner-City Youth. American Journal of Community Psychology, 32, 115-129. https://doi.org/10.1023/A:1025607226122

[42] Sacco, V.F. and Nakhaie, M.R. (2007) Fear of School Violence and the Ameliorative Effects of Student Social Capital. Journal of School Violence, 6, 3-25. https://doi.org/10.1300/J202v06n01_02

[43] Masten, A.S. and Coatsworth, J.D. (1998) The Development of Competence in Favorable and Unfavorable Environments: Lessons from Research on Successful Children. American Psychologist, 53, 205. https://doi.org/10.1037/0003-066X.53.2.205

[44] Masten, A.S. (2011) Resilience in Children Threatened by Extreme Adversity: Frameworks for Research, Practice, and Translational Synergy. Development and Psychopathology, 23, 493-506. https://doi.org/10.1017/S0954579411000198

[45] Graham-Bermann, S.A., Gruber, G., Howell, K.H. and Girz, L. (2009) Factors Dis- 
criminating among Profiles of Resilience and Psychopathology in Children Exposed to Intimate Partner Violence (IPV). Child Abuse and Neglect, 33, 648-660. https://doi.org/10.1016/j.chiabu.2009.01.002

[46] Werner, E.E. and Smith, R.S. (1982) Vulnerable But Not Invincible: A Study of Resilient Children. McGraw-Hill, New York.

[47] Pearlin, L.I. (1989) The Sociological Study of Stress. Journal of Health and Social Behavior, 30, 241-256. https://doi.org/10.2307/2136956

[48] Pearlin, L.I. (1999) The Stress Process Revisited: Reflections on Concepts and Their Interrelationships. In: Aneshensel, C.S. and Phelan, J.C., Eds., Handbook of the Sociology of Mental Health, Plenum, New York, 395-415. https://doi.org/10.1007/0-387-36223-1_19

[49] Turner, R.J. and Marino, F. (1994) Social Support and Social Structure: A Descriptive Epidemiology. Journal of Health and Social Behavior, 35, 193. https://doi.org/10.2307/2137276

[50] Margolin, G. and Gordis, E.B. (2000) The Effects of Family and Community Violence on Children. Annual Review of Psychology, 51, 445-479. https://doi.org/10.1146/annurev.psych.51.1.445

[51] Sousa, C., Herrenkohl, T.I., Moylan, C.A., Tajima, E.A., Klika, J.B., Herrenkohl, R.C. and Russo, M.J. (2011) Longitudinal Study on the Effects of Child Abuse and Children's Exposure to Domestic Violence, Parent-Child Attachments, and Antisocial Behavior in Adolescence. Journal of Interpersonal Violence, 26, 111-136. https://doi.org/10.1177/0886260510362883

[52] Aisenberg, E. and Herrenkohl, T. (2008) Community Violence in Context: Risk and Resilience in Children and Families. Journal of Interpersonal Violence, 23, 296-315. https://doi.org/10.1177/0886260507312287

[53] Aneshensel, C.S. (2005) Research in Mental Health: Social Etiology versus Social Consequences. Journal of Health and Social Behavior, 46, 221-228. https://doi.org/10.1177/002214650504600301

[54] Horwitz, A.V. (2002) Outcomes in the Sociology of Mental Health and Illness: Where Have We Been and Where Are We Going? Journal of Health and Social Behavior, 43, 143-151. https://doi.org/10.2307/3090193

[55] Gore, S. and Mangione, T.W. (1983) Social Roles, Sex Roles and Psychological Distress: Additive and Interactive Models of Sex Differences. Journal of Health and Social Behavior, 24, 300-312. https://doi.org/10.2307/2136397

[56] Yates, T., Dodds, M.F., Sroufe, L.A. and Egeland, B. (2003) Exposure to Partner Violence and Child Behavior Problems: A Prospective Study Controlling for Child Physical Abuse and Neglect, Child Cognitive Ability, Socioeconomic Status, and Life Stress. Development and Psychopathology, 15, 199-218. https://doi.org/10.1017/S0954579403000117

[57] Turner, R.J., Wheaton, B. and Lloyd, D.A. (1995) The Epidemiology of Social Stress. American Sociological Review, 60, 104-125. https://doi.org/10.2307/2096348

[58] Keyes, C.L.M. (2002) The Mental Health Continuum: From Languishing to Flourishing in Life. Journal of Health and Social Behavior, 43, 207-222.

https://doi.org/10.2307/3090197

[59] Pearlin, L.I., Menaghan, E.G., Lieberman, M.A. and Mullan, J.T. (1981) The Stress Process. Journal of Health and Social Behavior, 22, 337-356.

https://doi.org/10.2307/2136676 
[60] Ross, C.E. and Mirowsky, J. (1989) Explaining the Social Patterns of Depression: Control and Problem Solving-Or Support and Talking? Journal of Health and Social Behavior, 30, 206-219. https://doi.org/10.2307/2137014

[61] Copeland, E.P. and Hess, R.S. (1995) Differences in Young Adolescents' Coping Strategies Based on Gender and Ethnicity. Journal of Early Adolescence, 15, 203-219. https://doi.org/10.1177/0272431695015002002

[62] Thoits, P.A. (2006) Personal Agency in the Stress Process. Journal of Health and Social Behavior, 47, 309-323. https://doi.org/10.1177/002214650604700401

[63] Keyes, C.L.M. (1998) Social Well-Being. Social Psychology Quarterly, 61, 121-140. https://doi.org/10.2307/2787065

[64] Sampson, R.J., Raudenbush, S.W. and Earls, F. (1997) Neighborhoods and Violent Crime: A Multilevel Study of Collective Efficacy. Science, 277, 918. https://doi.org/10.1126/science.277.5328.918

[65] Tonry, M., Ohlin, L.E. and Farrington, D.P. (1991) Human Development and Criminal Behavior: New Ways of Advancing Knowledge. Springer-Verlag, New York. https://doi.org/10.1007/978-1-4613-9055-8

[66] Achenbach, T.M. (1991) Manual for the Youth Self-Report and 1991 Profile. University of Vermont Department of Psychiatry, Burlington.

[67] Drinkard, A.M. (2014) Predicting Prosociality among Urban Adolescents: Individual, Family, and Neighborhood Influences. Youth and Society, 49, 528-547. https://doi.org/10.1177/0044118X14543266

[68] Achenbach, T.M. (1991) Manual for the Child Behavior Checklist/4-18 and 1991 Profile. University of Vermont Department of Psychiatry, Burlington.

[69] Idler, E.L. and Benyamini, Y. (1997) Self-Rated Health and Mortality: A Review of Twenty-Seven Community Studies. Journal of Health and Social Behavior, 38, 21-37. https://doi.org/10.2307/2955359

[70] Turner, R.J., Frankel, B. and Levin, D. (1983) Social Support: Conceptualization, Measurement, and Implications for Mental Health. In: Greenley, J.R., Ed., Research in Community and Mental Health, Vol. 3, JAI Press, Greenwich, 67-111.

[71] Buka, S.L., Selner-O’Hagan, M.B., Kindlon, D.J. and Earls, F.J. (1997) The "My Exposure to Violence Interviews": Administration and Scoring Manual, Version 3. Harvard School of Public Health, Boston.

[72] Campbell, D.T. and Fiske, D.W. (1959) Convergent and Discriminant Validation by the Multitrait-Multimethod Matrix. Psychological Bulletin, 56, 81. https://doi.org/10.1037/h0046016

[73] Paternoster, R., Brame, R., Mazerolle, P. and Piquero, A. (1998) Using the Correct Statistical Test for the Equality of Regression Coefficients. Criminology, 36, 859-866. https://doi.org/10.1111/j.1745-9125.1998.tb01268.x

[74] StataCorp, L.P. (2014) Stata 13. StataCorp LP, College Station.

[75] Rutter, M. (2006) Implications of Resilience Concepts for Scientific Understanding. Annals of the New York Academy of Sciences, 1094, 1-12. https://doi.org/10.1196/annals.1376.002

[76] Benson, P.L. (2006) All Kids Are Our Kids. 2nd Edition, Jossey-Bass, San Francisco.

[77] Yearwood, E.L. (2003) Actual and Potential Violence: Communities Gripped in the Culture of Fear. Journal of Child and Adolescent Psychiatric Nursing, 16, 131-132. https://doi.org/10.1111/j.1744-6171.2003.00131.x 
[78] Sweatt, L., Harding, C.G., Knight-Lynn, L., Rasheed, S. and Carter, P. (2002) Talking about the Silent fear: Adolescents' Experiences of Violence in an Urban High-Rise Community. Adolescence, 37, 108-120.

[79] Patton, D.U., Woolley, M.E. and Hong, J.S. (2012) Exposure to Violence, Student Fear, and Low Academic Achievement: African American Males in the Critical Transition to High School. Children and Youth Services Review, 34, 388-395. https://doi.org/10.1016/j.childyouth.2011.11.009 